\title{
EDUCAÇÃO EM SAÚDE NA SALA DE ESPERA: UMA ABORDAGEM SOBRE AMAMENTAÇÃO
}

\author{
Simone Silva Santos ${ }^{1}$ \\ Norrama Araujo Santos ${ }^{2}$ \\ Marise Ramos Souza ${ }^{3}$ \\ Ivanildes Solange da Costa Barcelos ${ }^{4}$
}

\begin{abstract}
RESUMO: Este trabalho relata a experiência do projeto de extensão "Educação em saúde na sala de espera: uma abordagem sobre amamentação", realizado por alunas do curso de Enfermagem da Universidade Federal de Goiás em salas de espera de dez unidades de Estratégias de Saúde da Família (ESF), no Município de Jataí-GO, no qual se promoveu educação em saúde sobre o tema "amamentação e desmame precoce", entre os meses de novembro de 2010 e fevereiro de 2011. O objetivo foi contribuir para a qualidade de vida de crianças e mães, além de proporcionar uma formação integral, crítica, reflexiva e técnico-científica das graduandas envolvidas. Foram aplicados o método participativo e as técnicas de ensino, por meio de atividades educativas, para o público de mulheres gestantes, que aguardavam a consulta pré-natal, e mães de crianças de até dois anos de idade.
\end{abstract}

PALAVRAS-CHAVE: Educação em saúde. Aleitamento. Comunicação. Enfermagem.

\section{Health education in the waiting room: a breastfeeding approach}

\begin{abstract}
This paper reports the experience of the extension project "Health Education in the Waiting Room: a breastfeeding approach", performed by students of the Nursing Course at the Universidade Federal de Goiás in waiting rooms of ten Family Health Strategy units in the city of Jataí,GO, promoting health education on the theme "Breastfeeding and early weaning", from November 2010 to February 2011. With the aim of contribute to the quality of life of children and mothers, in addition provide in integral formation, critical, reflective and technical-scientific the students involved, were applied the participatory method and teaching techniques by means of educative activities, in the public of pregnant women who were waiting to prenatal visit and mothers of children up to two years.
\end{abstract}

KEYWORDS: Health education. Breastfeeding. Communication. Nursing.

\footnotetext{
Acadêmica do curso de Enfermagem da Universidade de Brasília (simoneone2@hotmail.com).

${ }^{2}$ Acadêmica do curso de Enfermagem da Universidade Federal de Goiás (Campus Jataí), bolsista do Programa de Educação Tutorial do curso de Enfermagem (norrama sma@hotmail.com).

${ }^{3}$ Mestre em Medicina Tropical pela Universidade Federal de Goiás, professora assistente no curso de Enfermagem da Universidade Federal de Goiás (Campus Jataí), vinculada ao Programa de Educação Tutorial do curso de Enfermagem desta universidade (msc_marise@hotmail.com).

${ }^{4}$ Doutora em Imunologia e Parasitologia Aplicadas pela Universidade Federal de Uberlândia, professora adjunta no curso de Enfermagem e de Biomedicina da Universidade Federal de Goiás (Campus Jataí), vinculada aos grupos de pesquisa Multidisciplinaridade e Saúde / Federal de Goiás; Diagnóstico de Parasitoses / Federal de Uberlândia; e ao NEPAI - Núcleo de Estudo e Pesquisa sobre o Adulto e Idoso: Perspectiva da Assistência à saúde / Federal de Goiás-UFG (solbarcelos1@hotmail.com).
} 


\section{INTRODUÇÃO}

De acordo com o Ministério da Saúde, a prática de aleitamento materno (AM) produz uma série de benefícios: a) para a criança: o aleitamento materno exclusivo até os seis meses de vida e a prorrogação desta prática, associada com outros alimentos, até os dois anos de idade, resultam em melhor qualidade de vida e diminuem o risco de adoecimento e morte; b) para a mulher que amamenta: há diminuição dos riscos de complicações após o parto, câncer de mama e ovários e de desenvolver diabetes; c) para a família, que economiza com a compra de alimentos e de remédios, tendo seus laços afetivos são reforçados; d) para o Sistema Único de Saúde (SUS): “com o aumento das taxas de AM, há redução de agravos à saúde de crianças e mulheres" (BRASIL, 2011, não paginado); e) para o país, que "terá cidadãos mais saudáveis e evitará gastos com remédios e internações hospitalares” (BRASIL, 2011, não paginado).

No Brasil, foi realizada pelo Ministério da Saúde, em 2008, uma Pesquisa Nacional sobre a Prevalência do Aleitamento Materno, a qual apontou que apenas 51,2\% das crianças recebem leite materno exclusivo até os seis meses de idade (BRASIL, 2009).

Para Agreli (2010, p. 19), "desmame é a introdução de qualquer tipo de alimento na dieta de uma criança, que até então se encontrava em regime de aleitamento materno exclusivo". Diversos fatores estão relacionados ao desmame precoce, dentre eles: o desconhecimento da mãe em relação à qualidade de seu leite (julgando ser fraco e não sustentar a criança), as crenças de que chás e sucos diminuem a incidência de cólicas no bebê e a falta de suporte cultural da família, na qual a cultura, a crença e os tabus influenciam, significativamente, na construção de uma herança sociocultural e no significado do aleitamento materno para a mulher, deixando o lactente exposto à diversas doenças (BECKER, 2012).

A educação em saúde é um importante instrumento de trabalho, principalmente quando utilizada como meio a problematização da realidade. Privilegiando-se o intercâmbio do conhecimento, no qual o saber profissional e o senso comum unem-se em prol do bom senso, tem-se a formação de uma conscientização e a construçãode indivíduos críticos e criadores. Esta analogia entre os diferentes saberes proporciona, ainda, um vínculo com a comunidade (CERVERA; PARREIRA; GOULART, 2011).

Nos processos educativos para promover a amamentação, o diálogo entre a lactante e o educador pode contribuir tanto para a desconstrução de mitos, quanto para agregar novos conhecimentos e atitudes positivas frente à amamentação, sendo de extrema importância os questionamentos e a explicação. $\mathrm{O}$ ensinar e aprender realiza-se de forma contínua e coletiva, por meio da troca de saberes e experiências, possibilitando, desta forma, que todos participem do processo de construção de conhecimento (MONTRONE et al., 2009).

O projeto "Educação em saúde na sala de espera: uma abordagem sobre amamentação" teve como objetivo contribuir para a qualidade de vida das crianças e mães, utilizando-se, para tanto, de atividades educativas, proporcionando uma formação integral, crítica, reflexiva e técnicocientífica das alunas do curso de Enfermagem envolvidas, por meio da realidade profissional. 


\section{METODOLOGIA}

O projeto teve como proposta abordar as gestantes e/ou mães de crianças com até dois anos de idade que aguardavam pela consulta de pré-natal ou puericultura nas salas de espera de dez unidades de Estratégias de Saúde da Família.

As mulheres envolvidas foram informadas sobre o projeto, sendo convidadas a participarem de uma atividade sobre o tema "Aleitamento materno e desmame precoce", com duração de 30 minutos. As participantes foram orientadas a formular perguntas e questionamentos sobre o que era apresentado, assim como expor suas experiências e outras dúvidas pertinentes ao assunto. Durante o diálogo, foram utilizados como recursos didáticos: álbum seriado, peça anatômica sintética e folderes informativos para promover o entendimento e o esclarecimento do público-alvo.

Na realização da atividade educativa, utilizou-se o método participativo, o qual foi tido como o mais adequado a este tipo de atividade. Este, por sua vez, além de oferecer informações necessárias à prática do aleitamento materno, também possibilita acolhimento às participantes, gerando segurança por estarem em conjunto com outras pessoas que estão vivenciando o mesmo momento. A metodologia em questão propicia, ainda, a livre comunicação e o questionamento do assunto em discussão, de maneira a fixar melhor o seu aprendizado. Foram utilizadas as técnicas de dinâmica de grupo e demonstração prática de alguns cuidados como, por exemplo, o preparo das mamas antes da amamentação.

O trabalho foi desenvolvido no período de novembro de 2010 a fevereiro de 2011 , em dias alternados, de segunda a sexta-feira, nos períodos matutino e vespertino, de acordo com os dias e horários específicos em que cada ESF oferecia consultas de pré-natal e puericultura.

\section{RESULTADOS E DISCUSSÃO}

No total, ocorreram 20 encontros (dois em cada ESF), nos quais foram desenvolvidas diversas discussões acerca da importância da amamentação. As dúvidas que mais se destacaram estiveram relacionadas às consequências do desmame precoce, assim como aos mitos perpetuados pela sociedade, como o caimento das mamas de quem amamenta; o leite ser fraco e não sustentar a criança; uso de chás para evitar cólicas nos bebês etc. Foi notável, durante as discussões, que a maioria das participantes sabia sobre os benefícios do aleitamento, contudo os malefícios eram desconhecidos.

Foi considerável a satisfação das participantes diante do esclarecimento de suas dúvidas e, principalmente, da troca de experiência entre elas, da atenção do grupo de esclarecimento para ouvir suas angústias, dúvidas e atendê-las com um olhar diferenciado, o que não é tão comum nas consultas pré-natais. Esta condição possibilitou a sensação de segurança e promoveu a capacidade de oferecer apoio, com presteza e de acordo com as necessidades percebidas (REBERTE; HOGA, 2010).

Nessa atividade, foi possível detectar, por meio das expressões das participantes e da troca 
de experiências, falhas vindas dos profissionais que realizam a consulta pré-natal, seja no esclarecimento sobre a importância do aleitamento materno ou mesmo em simples orientações, como, por exemplo, o preparo das mamas antes da amamentação, quais as posições corretas para amamentar, as exceções em que não se deve amamentar, entre outras.

Os momentos vivenciados com as participantes permitiram às graduandas não só ensinar a essas mães, mas aprender com elas, por meio dos gestos, palavras trocadas e atitudes frente ao assunto, proporcionando uma visão diferenciada sobre o processo de construção de uma assistência integral, digna e humanizada, sendo essa uma importante experiência para a formação de profissionais de Enfermagem, que vão além da técnica em si e avaliam o paciente como um todo.

Comumente, a sala de espera é vista, de forma negativa, como o local no qual as pessoas apresentam diversos sentimentos de ansiedade, medo, tristeza e angústia por ficar muito tempo aguardando pelo atendimento e pelo resultado (FRIZON et al., 2011). Entretanto, trata-se de um espaço rico e dinâmico, em que diversas pessoas transitam e, por meio de interações, trocam sentimentos e experiências pela linguagem ou pelas expressões (TEIXEIRA; VELOSO, 2006). Sendo assim, a escolha da sala de espera se deve ao fato de ser este um espaço ideal para a atuação de diversos profissionais da saúde, dentre eles, destacamos o enfermeiro, por ter subsídios técnicos e científicos para desenvolver a educação em saúde, minimizar os sentimentos negativos e oferecer acolhimento por intermédio da escuta e do diálogo.

A prática de ensino-aprendizagem permite, ao acadêmico, desenvolver sua capacidade de comunicação, interação com o usuário dos serviços de assistência à saúde, práticas educativas e, principalmente, formar profissionais críticos e reflexivos, aptos a viverem em um mundo de constantes transformações, capazes de construir novos conhecimentos a partir da realidade vista ao seu redor, tornando-os indivíduos dotados de profundo senso ético e humano (VALENTE; VIANA, 2009).

É extremamente importante ao graduando em Enfermagem desenvolver a capacidade de comunicação com o público, principalmente por meio da participação em atividades de educação em saúde. Dessa forma, é possível adquirir uma visão diferenciada e perceber os pacientes como pessoas, cidadãos que podem se transformar e contribuir para mudanças sociais e não somente como portadores de necessidades.

Neste sentido, a extensão universitária vem contribuir com a formação acadêmica desses alunos, fornecendo o espaço e o acolhimento adequados para o desenvolvimento das capacidades e da articulação dos graduandos enquanto grupo.

A extensão universitária diz respeito ao estreitamento de laços com a sociedade, proporcionando condições para que o conhecimento transforme-se em sabedoria. É um processo educativo, cultural e científico, que articula o ensino e a pesquisa de forma indissociável, resultando em inúmeros benefícios. Além disso, promove a compreensão da existência humana, transcendendo a ideia de que a busca por conhecimento e aperfeiçoamento dos saberes tenha se resumido à mera busca por dinheiro e pelo poder (ARROYO; ROCHA, 2010). 


\section{CONSIDERAÇÕES FINAIS}

A educação em saúde constitui uma ferramenta de trabalho importante que propicia tanto a identificação de uma problemática quanto a busca de soluções. Tratando-se da importância do aleitamento materno e da intenção de diminuir o desmame precoce, essa ferramenta possui importância ainda maior, levando em consideração que a falta de conhecimento é um dos fatores de maior peso na interrupção da amamentação.

Como resultado da educação em saúde, promovida nas salas de espera das ESF, evidenciou-se a capacidade de entretenimento das mães que aguardavam suas consultas, ao mesmo tempo em que adquiriam conhecimentos indispensáveis para o bom desenvolvimento de seus filhos, esclarecendo dúvidas e diminuindo a angústia e o medo decorrentes do não conhecimento sobre os temas.

Concomitantemente, as graduandas foram capacitadas para o exercício de promoção da saúde por intermédio da educação, possibilitando o desenvolvimento de estratégias dinâmicas em espaços antes não trabalhados. Ressaltando que a orientação não deve ser realizada e concentrada apenas em consultórios, e sim onde for possível, tornando o ambiente de espera um lugar de aquisição do conhecimento.

A respeito da relevância dessa experiência para as estudantes do curso de Enfermagem, a extensão universitária proporcionou espaço de vivência da realidade e construção de uma formação integral, crítica, reflexiva e técnico-científica.

Além de ajudar na formação de uma cultura favorável à amamentação em diversas comunidades, a experiência propiciada por este trabalho também passa a fazer parte da vida dessas mulheres, que, possivelmente, terão atitudes de valorização da prática da amamentação.

\section{REFERÊNCIAS}

AGRELI, R. M. O aleitamento materno e as causas de desmame precoce: uma revisão bibliográfica. 2010. 36f. Trabalho de Conclusão de Curso (Especialização em Atenção Básica em Saúde da Família) - Universidade Federal de Minas Gerais, Belo Horizonte, 2010.

ARROYO, D. M. P.; ROCHA M. S. P. M. L. Meta-avaliação de uma extensão universitária: estudo de caso. Avaliação, Campinas, v. 15, n. 2, p. 135-161, 2010.

BECKER, B. B. As causas da interrupção precoce do aleitamento materno no Brasil. 2012. Disponível em: < http://bibliodigital.unijui.edu.br:8080/xmlui/bitstream/handle/123456789/571/ Artigo.pdf? sequence=1>. Acesso em: 22 jan. 2012.

BRASIL. Ministério da Saúde. Secretaria de Atenção à Saúde. Área Técnica de Saúde da Criança e Aleitamento Materno. Rede Amamenta Brasil: os primeiros passos (2008-2010). Brasília: Ministério da Saúde, 2011. 

brasileiras e DF. 2009. Disponível em: < http://portal.saude.gov.br>. Acesso em: 22 jan. 2012. CERVERA, D. P. P.; PARREIRA, B. D. M.; GOULART, B. F. Educação em saúde: percepção dos enfermeiros da atenção básica em Uberaba-MG. Ciênc. \& Saúde Coletiva, Rio de Janeiro, v. 16, n. 1, p. 1547-1554, 2011.

FRIZON, G. et al. Familiares na sala de espera de uma Unidade de Terapia Intensiva: sentimentos revelados. Rev. Gaúcha Enferm., Porto Alegre, v. 32, n. 1, p. 72-78, 2011.

MONTRONE, A. V. G. et al. Promoção da amamentação por crianças do ensino fundamental. Interface: Comunicação, Saúde, Educação, Botucatu, v. 13, n. 31, p. 449-459, 2009.

REBERTE, L. M.; HOGA, L. A. K. A experiência de pais participantes de um grupo de educação para saúde no pré-natal. Ciência y Enfermeria, Casilha, v. 16, n. 1, p. 105-114, 2010.

TEIXEIRA, E. R.; VELOSO, R. C. O grupo em sala de espera: território de práticas e representações em saúde. Texto Contexto Enferm., Florianópolis, v. 15, n. 2, p. 320-325, 2006.

VALENTE, G. S. C.; VIANA, L. O. Da formação por competências à prática docente reflexiva. Revista Iberoamericana de Educación, v. 48, n. 4, 2009. 